\title{
Positive end-expiratory pressure titration via esophageal balloon monitoring in a morbidly obese patient undergoing laparoscopic nephrectomy
}

\author{
Nicholas J. Alvey, MD • Maung Hlaing, MD · Jerome Piccoli, RRT • \\ Naveen Kukreja, MD $\cdot$ Timothy T. Tran, MD $(\mathbb{0}$
}

Received: 11 December 2019/Revised: 12 February 2020/Accepted: 12 February 2020/Published online: 3 March 2020

(C) Canadian Anesthesiologists' Society 2020

\section{To the Editor,}

Positive end-expiratory pressure (PEEP) is commonly used during mechanical ventilation to prevent atelectasis and small airway collapse during the respiratory cycle. ${ }^{1}$ There has been some success in using transpulmonary pressure to titrate PEEP to optimize oxygenation in the critical care environment. ${ }^{2}$ Ventilation of the surgical patient can be challenging because of factors such as patient positioning, abdominal insufflation, and patient body habitus. ${ }^{3,4}$

We used the estimated transpulmonary pressure (eTPP) measured via an esophageal balloon monitor (EBM) to optimize oxygenation and pulmonary mechanics in a 34yr-old female with super morbid obesity (body mass index of $73 \mathrm{~kg} \cdot \mathrm{m}^{-2}$ ) and left renal cell carcinoma mass who presented for a robotic radical left nephrectomy.

The patient (who provided consent for this report) was brought to the operating room and placed on high flow (10 $\mathrm{L} \cdot \mathrm{min}^{-1}$ ) oxygen using regular nasal prongs. Induction and endotracheal intubation were completed without difficulty. Total intravenous anesthesia with propofol was used maintaining the patient state index (Sedline; Masimo Corporation, CA, USA) at 30-50; neuromuscular blockade was obtained with rocuronium. Mechanical ventilation was commenced with a Hamilton G5 ventilator (Hamilton Medical, NV, USA) from the

N. J. Alvey, MD · M. Hlaing, MD · N. Kukreja, MD ·

T. T. Tran, MD ( $₫)$.

Department of Anesthesiology, University of Colorado -

Anschutz Medical Campus, Aurora, CO, USA

e-mail: ttran@wustl.edu

J. Piccoli, RRT

Division of Pulmonary Medicine, UCHealth, Aurora, CO, USA intensive care unit, using the adaptive pressure ventilation mode at set parameters of tidal volume 350 $\mathrm{mL}$, respiratory rate 20 breaths $\mathrm{min}^{-1}$, and PEEP of 16 $\mathrm{cmH}_{2} \mathrm{O}$.

An EBM (Cooper Surgical Medical Devices, CT, USA) was inserted and its location was confirmed by the presence of cardiac oscillations on the monitor with appropriate changes in waveform with abdominal compressions. The patient was then rotated to the lateral position. The initial eTPP curves showed a negative pressure of $4.6 \mathrm{cmH}_{2} \mathrm{O}$ at end-expiration (Figure A). The initial arterial blood gas (ABG) showed $\mathrm{pH} 7.38$; partial pressure of carbon dioxide, $47 \mathrm{mmHg}$; partial pressure of oxygen, $91 \mathrm{mmHg}$; bicarbonate, $28 \mathrm{mEq} \cdot \mathrm{L}^{-1}$ and base excess, 1.9; and an associated partial pressure of arterial oxygen to fraction of inspired oxygen $(\mathrm{P} / \mathrm{F})$ ratio of 111 . The PEEP was increased from 16 to $20 \mathrm{cmH}_{2} \mathrm{O}$, which reduced the eTPP to 0 at end-expiration (Figure $\mathrm{B}$ ).

With abdominal insufflation, a negative end-expiratory eTPP occurred so the PEEP was increased to $25 \mathrm{cmH}_{2} \mathrm{O}$, with an improvement in the end-expiratory eTPP ( 0 $\mathrm{cmH}_{2} \mathrm{O}$ ). The patient maintained this pressure curve throughout the robotic portion of the case, while the fraction of inspired oxygen was reduced from $70 \%$ to $50 \%$. Repeat ABG approximately $90 \mathrm{~min}$ showed an improved $\mathrm{P} / \mathrm{F}$ ratio from 174 to 226 . When the abdomen was opened for specimen retrieval, the decrease in intraabdominal pressure predictably increased the endexpiratory eTPP to greater than 0 . This reduced the PEEP to $22 \mathrm{cmH}_{2} \mathrm{O}$ while maintaining an end-expiratory eTPP of $0 \mathrm{cmH}_{2} \mathrm{O}$. A positive end-expiratory eTPP indicates that the airway pressure exceeds the pleural pressure, which may lead to alveolar overdistention. At the conclusion of the case, the patient was transported to the intensive care unit and successfully extubated to 
(A)

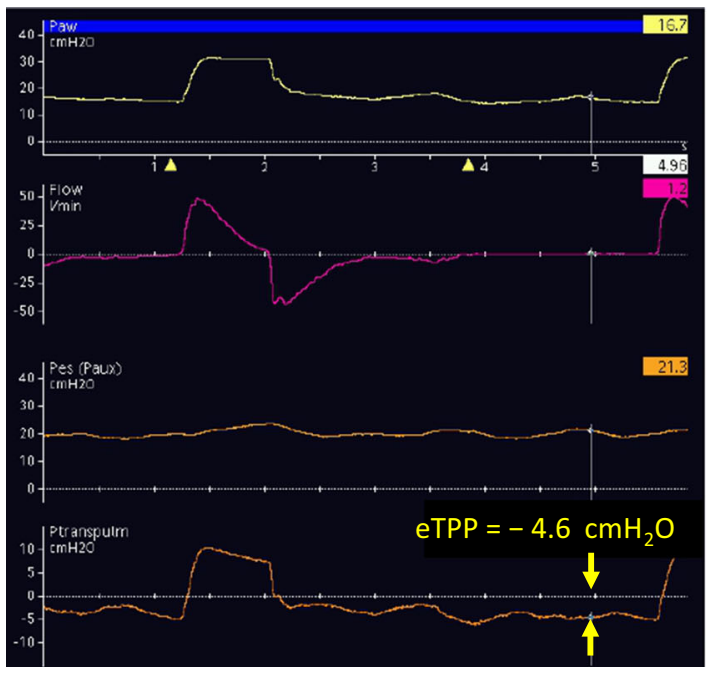

(B)

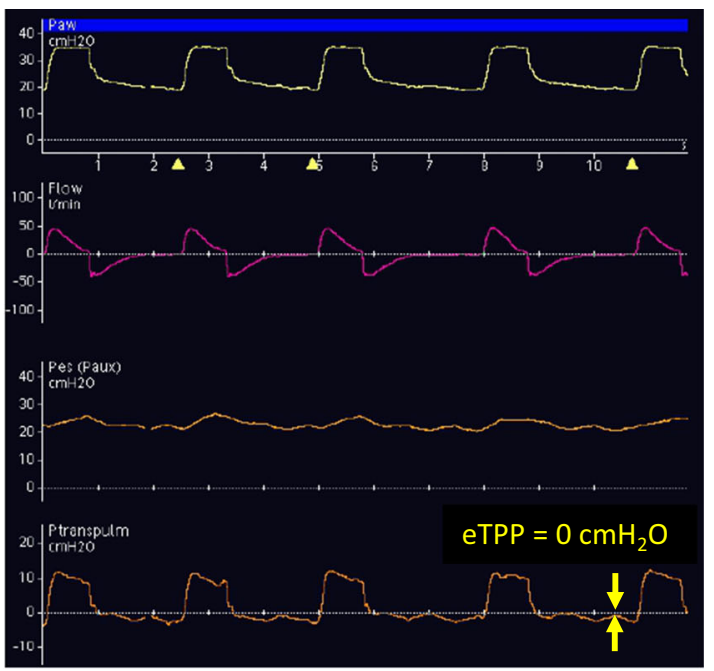

Figure (A) The initial pressure curves as seen on the ventilator showing the airway pressure, airflow velocity, esophageal pressure (after esophageal balloon monitor placement), and the estimated transpulmonary pressure $(\mathrm{eTPP}=$ airway pressure-esophageal pressure). The yellow arrows show an eTPP of negative $4.6 \mathrm{cmH}_{2} \mathrm{O}$ at end-expiration, which suggests that the pleural pressure exceeds the airway pressure, which can result in alveolar collapse and atelectrauma. Note that the airflow velocity is $0 \mathrm{~L} \cdot \mathrm{min}^{-1}$, ensuring

continuous positive airway pressure ventilation the next day.

This case shows the successful use of eTPP using an EBM to titrate PEEP in an effort to optimize patient oxygenation and pulmonary mechanics during surgery. Better knowledge of a patient's pleural pressures during surgery may allow an anesthesia provider to use nontraditional ventilator settings knowing that harm is not being caused by the PEEP or increased airway pressures. These maneuvers may reduce the likelihood of both atelectasis and alveolar overdistention by titrating the PEEP to an end-expiration eTTP of 0.

\section{Conflicts of interest None.}

Funding statement None.

Editorial responsibility This submission was handled by Dr. Hilary P. Grocott, Editor-in-Chief, Canadian Journal of Anesthesia. minimal airway resistance, which allows for more accurate measurement of the esophageal pressure. (B) Pressure curves after increasing the positive end-expiratory pressure (PEEP) from 16 to 20 $\mathrm{cmH}_{2} \mathrm{O}$. The PEEP was titrated to a goal of an end-exhalation eTPP of $0 \mathrm{cmH}_{2} \mathrm{O}$ (yellow arrows) where pleural pressures do not exceed airway pressures and the alveoli do not collapse during the respiratory cycle.

\section{References}

1. Spadaro S, Karbing DS, Mauri T, et al. Effect of positive endexpiratory pressure on pulmonary shunt and dynamic compliance during abdominal surgery. Br J Anaesth 2016; 116: 855-61.

2. Talmor D, Sarge T, Malhotra A, et al. Mechanical ventilation guided by esophageal pressure in acute lung injury. N Engl J Med 2008; 359: 2095-104.

3. Fumagalli J, Berra L, Zhang $C$, et al. Transpulmonary pressure describes lung morphology during decremental positive endexpiratory pressure trials in obesity. Crit Care Med 2017; 45: 1374-81.

4. Stahl DL, North CM, Lewis A, Kimberly WT, Hess DR. Case scenario: power of positive end-expiratory pressure: use of esophageal manometry to illustrate pulmonary physiology in an obese patient. Anesthesiology 2014; 121: 1320-6.

Publisher's Note Springer Nature remains neutral with regard to jurisdictional claims in published maps and institutional affiliations. 